\title{
Oxygenated Biofuels from Butanol for Diesel Blends: Synthesis of the Acetal 1,1-Dibutoxyethane Catalyzed by Amberlyst-15 Ion-Exchange Resin
}

\author{
Nuno S. Graça, ${ }^{\dagger}$ Luís S. Pais, ${ }^{*}$ Viviana M. T. M. Silva, ${ }^{\dagger}$ and Alírio E. Rodrigues, ${ }^{*}$ \\ Laboratory of Separation and Reaction Engineering (LSRE), Department of Chemical Engineering, Faculty of \\ Engineering, University of Porto, Rua Dr. Roberto Frias s/n, 4200-465 Porto, Portugal, and School of \\ Technology and Management, Bragança Polytechnic Institute, Campus de Santa Apolónia, Apartado 1134, \\ 5301-857 Bragança, Portugal
}

\begin{abstract}
The synthesis of 1,1-dibutoxyethane or acetaldehyde dibutylacetal was studied in a batch reactor by reacting butanol and acetaldehyde in a liquid phase, using Amberlyst-15 as the catalyst. The reaction equilibrium constant was experimentally determined in the temperature range $20-40{ }^{\circ} \mathrm{C}$ at 6 atm, where $K_{\mathrm{a}}=0.00959$ $\exp [1755.3 / T(\mathrm{~K})]$. The standard properties of the reaction at $298.15 \mathrm{~K}$ were estimated: $\Delta H^{\circ}=-14.59 \mathrm{~kJ}$ $\mathrm{mol}^{-1}, \Delta G^{\circ}=-3.07 \mathrm{~kJ} \mathrm{~mol}^{-1}$, and $\Delta S^{\circ}=-38.64 \mathrm{~J} \mathrm{~mol}^{-1} \mathrm{~K}^{-1}$. Kinetic experiments were performed in the temperature range $10-50{ }^{\circ} \mathrm{C}$ at 6 atm. A two-parameter kinetic law based on a Langmuir-Hinshelwood rate expression, using activity coefficients from the UNIFAC method, was used. The kinetic parameters are $k_{\mathrm{c}}=$ $2.39 \times 10^{9} \exp [-6200.9 / T(\mathrm{~K})]\left(\mathrm{mol} \mathrm{g}_{\mathrm{cat}}{ }^{-1} \mathrm{~min}^{-1}\right)$ and $k_{\mathrm{s}, \mathrm{D}}=2.25 \times 10^{-4} \exp [3303.1 / T(\mathrm{~K})]$. The activation energy of the reaction is $51.55 \mathrm{~kJ} \mathrm{~mol}^{-1}$. This work is an important step for further implementation of an integrated reaction-separation process, such as a simulated moving-bed reactor.
\end{abstract}

\section{Introduction}

In the last years, there has been a growing interest in the development of environmentally friendly gasoline and diesel fuels. Oxygenated additives can be used in order to reduce $\mathrm{HC}$ and $\mathrm{CO}$ emissions and provide a high octane quality of unleaded gasoline. ${ }^{1}$ The increase of the oxygen content in diesel fuel reduces significantly the particulate levels; studies showed that the Bosh smoke number (a measure of the particulate or soot levels in diesel exhaust) falls from about $55 \%$ for conventional diesel fuel to less than $1 \%$ when the oxygen content of the fuel is above about $25 \%$ by mass. ${ }^{2}$ Methyl and ethyl tert-butyl ether (MTBE and ETBE, respectively) are widely used as gasoline additives, providing enhancement of the octane number and a significant reduction of tailpipe pollution. However, these ethers are not suitable as diesel oxygenates because they drastically reduce the cetane number in diesel blends; for example, the ETBE cetane number is $2.5,{ }^{3}$ with the minimum value being 51, according to directive 2003/17/EC. Acetals have been under consideration as oxygenated additives to diesel fuel. ${ }^{4}$ The use of the acetal 1,1-diethoxyethane as a diesel fuel additive has shown a marked reduction of exhaust smoke. ${ }^{5}$ Moreover, acetals are useful as raw materials for perfumes, agricultural chemicals, and pharmaceuticals; ${ }^{6}$ they also can be used in the flavoring of food, in the design of synthetic perfumes, ${ }^{7,8}$ as a mineral oil substitute, ${ }^{9}$ in the production of poly(vinylic ether)s, and as an intermediate in condensation reactions. ${ }^{10,11}$

Acetals can be produced by the acid-catalyzed addition of 2 mol of monohydric alcohol and $1 \mathrm{~mol}$ of aldehyde. ${ }^{12}$ There is a particular interest in the use of ethanol and acetaldehyde as reactants because they are subproducts of the cane sugar industry, and therefore DEE or acetaldehyde diethylacetal can be produced by means of natural resources. ${ }^{13}$ Recently, butanol has been considered as an alternative to ethanol as a biofuel. ${ }^{14}$ Butanol has several advantages over ethanol, such as higher

* To whom correspondence should be addressed. Tel.: +351225081671. Fax: +351225081674. E-mail: arodrig@fe.up.pt.

${ }^{\dagger}$ University of Porto.

Bragança Polytechnic Institute. energy content, lower water absorption, better blending ability, and use in conventional combustion engines without modifications. Therefore, butanol is also a possible bioderivable reactant to produce the acetal DBE or acetaldehyde dibutylacetal.

The synthesis of acetals is typically carried out under conditions of homogeneous catalysis; ${ }^{15}$ however, the use of strong liquid inorganic acids like $\mathrm{H}_{2} \mathrm{SO}_{4}, \mathrm{HCl}$, and $\mathrm{HI}$ as the catalyst brings some disadvantages, namely, separation problems due to miscibility with a reaction medium and equipment corrosion at a high catalyst concentration. ${ }^{16,17}$ Therefore, heterogeneous catalysts, such as ion-exchange resins and zeolites, ${ }^{18,19}$ become a safer alternative for acetal production. Previous works report the use of heterogeneous catalysts for synthesis of the acetal 1,1-diethoxyethane using Amberlyst-15 and $-18^{13,20}$ and the acetal 1,1-dimethoxyethane using Amberlyst-15, a Y-type zeolite, and SMOPEX 101 fibres. ${ }^{21,22}$

Amberlyst-15 proved to be an efficient catalyst for acetalization of butanol with heptanal ${ }^{23}$ and formaldehyde, ${ }^{24}$ however, it was verified that side reactions are influenced by the type of ion-exchange resins in the esterification of $n$-butanol with acetic acid at $100-120{ }^{\circ} \mathrm{C}$. The observed side reaction products using Purolite CT 269 (monosulfonated) and Amberlyst-48 (bisulfonated) were isomers of butene, di-n-butyl ether, and sec-butyl$n$-butyl ether as well as sec-butanol and sec-butyl acetate, whereas with Amberlyst-46 (surface-sulfonated), side reactions were almost negligible. ${ }^{25}$

In this work, synthesis of the acetal 1,1-dibutoxyethane (DBE) from butanol and acetaldehyde by means of a liquid-phase reaction catalyzed by Amberlyst-15 is studied in order to obtain thermodynamic and kinetic data for further implementation of the integrated reaction-separation processes of fixed-bed reactors and simulated moving bed reactors (SMBRs). Because the reaction is equilibrium-limited, the use of an integrated reactionseparation process, such as a SMBR, allows the displacement of chemical equilibrium toward product formation..$^{20,26}$ 


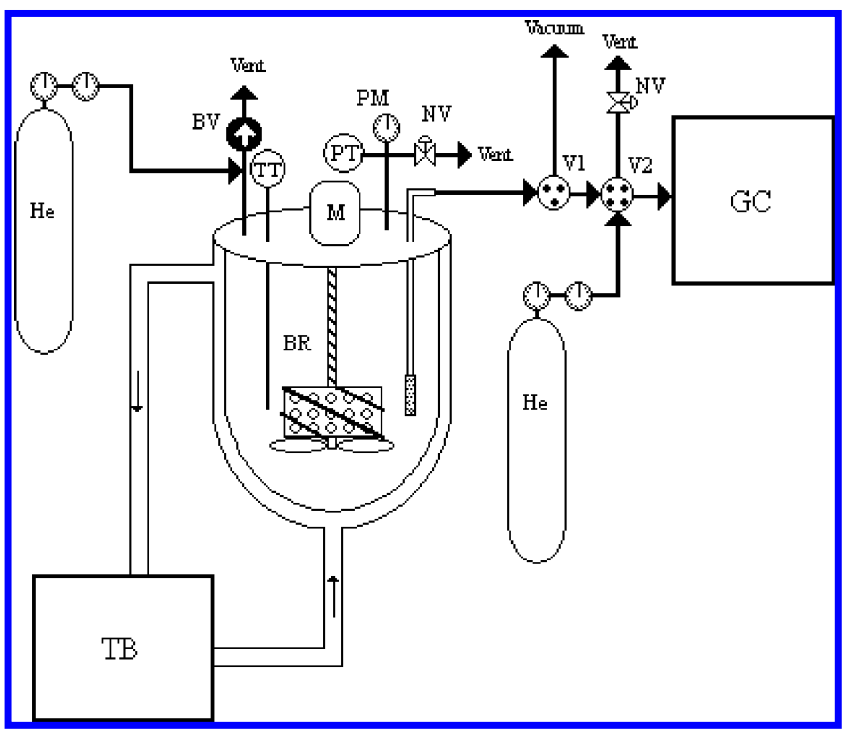

Figure 1. Experimental setup for kinetic studies: BR, batch reactor; $M$, motor; TT, temperature sensor; PT, pressure sensor; PM, manometer; BV, blow-off valve; V1, sampling valve; $\mathrm{V} 2$, injection valve; $\mathrm{NV}$, needle valve; $\mathrm{GC}$, gas chromatograph; TB, thermostati bath.

\section{Experimental Section}

2.1. Reactor. The experiments were carried out in a glassjacketed $1 \mathrm{dm}^{3}$ autoclave (Büchi, Flawil, Switzerland), operating in a batch mode, mechanically stirred, equipped with pressure and temperature sensors and with a blow-off valve. The temperature was controlled by thermostatted water (Lauda, Lauda-Königshofen, Germany) that flows through the jacket. To maintain the reacting mixture in the liquid phase over the whole temperature range, the reactor was pressurized with helium. Figure 1 shows a schematic representation of the experimental setup. A dry catalyst is placed in a basket at the top of the stirrer shaft and falls down in the reactant solution at the beginning of agitation; therefore, the time zero for the reaction is well-defined. One of the outlets of the reactor was connected to the liquid sampling valve (Valco, Houston, TX), which injects $0.1 \mu \mathrm{L}$ of pressurized liquid into a gas chromatograph.

2.2. Catalyst. The catalyst used was the ion-exchange resin Amberlyst-15 (Rohm and Haas, Philadelphia, PA). The ionexchange capacity is 4.7 mequiv $\mathrm{g}_{\text {dry resin }}{ }^{-1}$, and the surface area is $53 \mathrm{~m}^{2} \mathrm{~g}^{-1}$.

2.3. Chemicals. The reactants used were butanol ( $>99.9 \%$ pure) and acetaldehyde ( $>99.5 \%$ pure) (Sigma-Aldrich, Madison, WI).

2.4. Analytical Method. The samples were analyzed on a gas chromatograph (Chrompack 9100; Varian, Palo Alto, CA), and the compounds were separated in a fused-silica capillary column (Chrompack CP-Wax $57 \mathrm{CB}$ ), $25 \mathrm{~m} \times 0.53 \mathrm{~mm}$ i.d., and $\mathrm{df}=22.0 \mu \mathrm{m}$ using a thermal conductivity detector (TCD 903 A) for peak detection. The column temperature was programmed with a $5 \mathrm{~min}$ initial hold at $75^{\circ} \mathrm{C}$, followed by a $25^{\circ} \mathrm{C} \mathrm{min}{ }^{-1}$ ramp up to $100{ }^{\circ} \mathrm{C}$, where it was held for $1.5 \mathrm{~min}$. The temperature of the injector was set at $150{ }^{\circ} \mathrm{C}$. The carrier gas used was Helium N50.

\section{Thermodynamic Equilibrium Constant}

$\mathrm{DBE}$ and water are produced by the acid-catalyzed addition of $2 \mathrm{~mol}$ of butanol and $1 \mathrm{~mol}$ of acetaldehyde:

2 butanol (A) + acetaldehyde (B) $\Leftrightarrow \operatorname{DBE}(\mathrm{C})+$ water (D)
Table 1. Experimental Equilibrium Compositions and Equilibrium Constants $^{a}$

\begin{tabular}{lrrrr}
\hline & \multicolumn{4}{c}{$T(\mathrm{~K})$} \\
\cline { 2 - 5 } & 293.15 & 303.15 & 313.15 & 323.15 \\
\hline$x_{\mathrm{A}}$ & 0.40720 & 0.42078 & 0.43979 & 0.45274 \\
$x_{\mathrm{B}}$ & 0.16090 & 0.16742 & 0.17362 & 0.17915 \\
$x_{\mathrm{C}}$ & 0.21595 & 0.20590 & 0.19330 & 0.18406 \\
$x_{\mathrm{D}}$ & 0.21595 & 0.20590 & 0.19330 & 0.18406 \\
$K_{x}$ & 1.74794 & 1.43165 & 1.11269 & 0.92256 \\
$\gamma_{\mathrm{A}}$ & 1.07895 & 1.08250 & 1.08363 & 1.08343 \\
$\gamma_{\mathrm{B}}$ & 1.14948 & 1.14763 & 1.14400 & 1.14096 \\
$\gamma_{\mathrm{C}}$ & 1.38198 & 1.38971 & 1.40227 & 1.40939 \\
$\gamma_{\mathrm{D}}$ & 2.11094 & 2.16536 & 2.21667 & 2.27337 \\
$K_{\gamma}$ & 2.17916 & 2.23767 & 2.31391 & 2.39235 \\
$K_{\mathrm{a}}=K_{x} K_{\gamma}$ & 3.80905 & 3.20023 & 2.57467 & 2.20709 \\
${ }^{a}$ Experimental conditions: $w_{\text {cat }}=1.8 \mathrm{~g}, V=530 \mathrm{~mL}, P=6$ atm, & $=3$. \\
$r_{\mathrm{A} / \mathrm{B}}=2.2$, and 0.5 mm $<d_{\mathrm{p}}<0.6 \mathrm{~mm}$. & &
\end{tabular}

The equilibrium constants based on activities ${ }^{27}$ as shown in eq 1 were calculated for different temperatures (in the range of 293.15-323.15 K), at $6 \mathrm{~atm}$, at a stoichiometric initial molar ratio of reactants butanol/acetaldehyde $\left(r_{\mathrm{A} / \mathrm{B}}=2.2\right)$; the total volume of the reactants was $530 \mathrm{~mL}$ and the mass of the catalyst $1.8 \mathrm{~g}$. It was ensured that, for these conditions, the amounts of adsorbed species are negligible, and there was only one liquid phase in spite of the fact that water and $n$-butanol are only partially miscible; therefore, the equilibrium composition is only related to the thermodynamic reaction equilibrium. Moreover, it was not detected any byproduct. The equilibrium constants were calculated from the experimentally measured equilibrium composition and activity coefficients of the species $\left(\gamma_{i}\right)$ calculated by the UNIFAC method (Table 1$).{ }^{28}$ The parameters used are presented in Appendix A.

$$
K_{\mathrm{a}}=\frac{a_{\mathrm{C}} a_{\mathrm{D}}}{a_{\mathrm{A}}^{2} a_{\mathrm{B}}}=\frac{x_{\mathrm{C}} x_{\mathrm{D}}}{x_{\mathrm{A}}{ }^{2} x_{\mathrm{B}}} \frac{\gamma_{\mathrm{C}} \gamma_{\mathrm{D}}}{\gamma_{\mathrm{A}}^{2} \gamma_{\mathrm{B}}}=K_{\mathrm{X}} K_{\gamma}
$$

At equilibrium, the standard free-energy change is related to the equilibrium constant by

$$
\Delta G^{\circ}=-R T \ln K_{a}
$$

By definition, the standard free-energy change is related to standard enthalpy and entropy changes by

$$
\Delta G^{\circ}=\Delta H^{\circ}-T \Delta S^{\circ}
$$

Therefore, temperature dependence of the equilibrium constant is given by

$$
\ln K_{\mathrm{a}}=\frac{\Delta S^{\circ}}{R}-\frac{\Delta H^{\circ}}{R} \frac{1}{T}
$$

The standard free energy, enthalpy, and entropy changes for this reaction can be estimated by fitting experimental values of $\ln K_{\text {eq }}$ vs $1 / T$ (Figure 2). From the slope, it is concluded that the reaction is slightly exothermic with $\Delta H^{\circ}=-14593.6 \mathrm{~J}$ $\mathrm{mol}^{-1}$, and from the intercept, $\Delta S^{\circ}=-38.6 \mathrm{~J} \mathrm{~mol}^{-1} \mathrm{~K}^{-1}$ and $\Delta G^{\circ}=-3074.1 \mathrm{~J} \mathrm{~mol}^{-1}$ calculated from eq 3 .

\section{Kinetic Results}

The influence of the external mass-transfer resistance was studied by performing experiments at different stirring speeds. The external mass-transfer resistance is eliminated for a stirring speed above $800 \mathrm{rpm}$. Therefore, all further experiments were carried out at $800 \mathrm{rpm}$. 


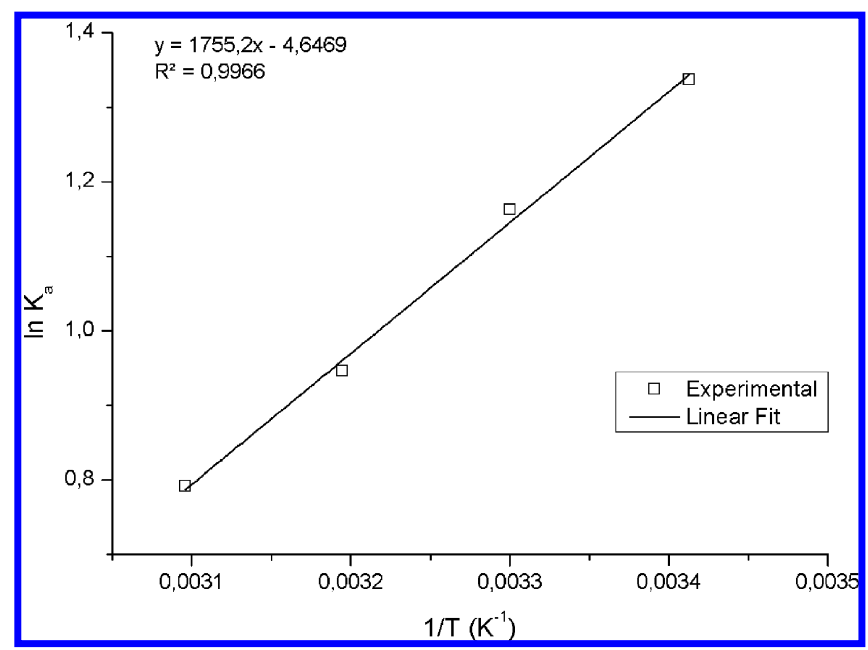

Figure 2. Linearization of the experimental equilibrium constants.

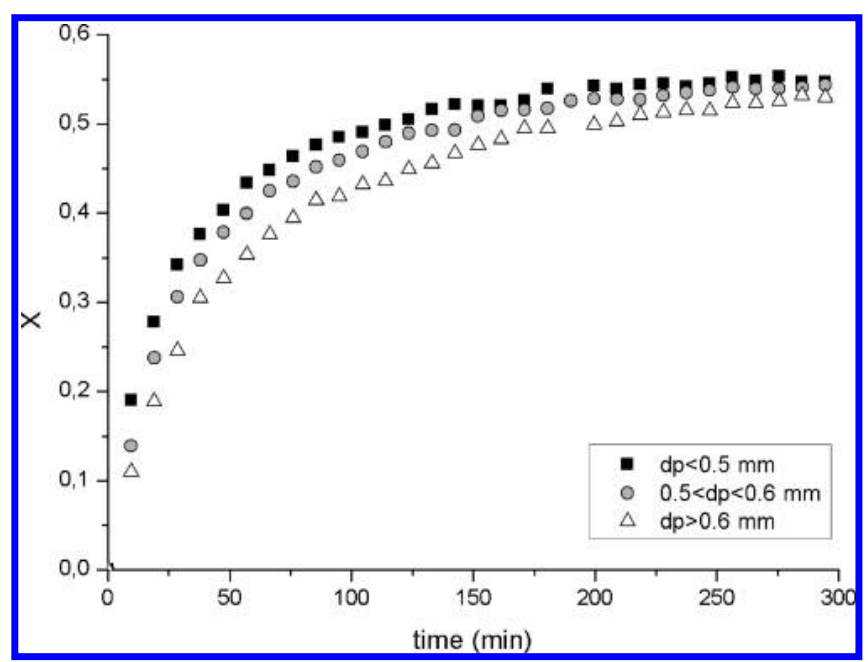

Figure 3. Effect of the particle size on the conversion of the acetaldehyde history: $T=293.15 \mathrm{~K}, P=6 \mathrm{~atm}, r_{\mathrm{A} / \mathrm{B}}=2.2, w_{\text {cat }}=1.8 \mathrm{~g}$, and $V=$ $530 \mathrm{~mL}$.

4.1. Effect of the Particle Size. Determination of the concentration of acidic sites of Amberlyst-15 resin for different particle diameters ${ }^{29}$ shows that the concentration of acid sites is independent of the particle size; therefore, any difference in reaction kinetics for different particle sizes can only be attributed to the internal mass-transfer resistance.

Experiments carried out with different particle sizes of the catalyst show internal diffusion limitations for experiments with particle diameters greater than $0.5 \mathrm{~mm}$ (Figure 3). For diameters of particles below $0.5 \mathrm{~mm}$, it is not possible make conclusions about internal diffusion limitations. Therefore, the kinetic parameters will be estimated by using a detailed model accounting for intraparticle diffusion.

4.2. Mass of the Catalyst Effect. The conversion increases with an increase in the mass of the catalyst (Figure 4) for the same experimental conditions.

The maximum reaction rate occurs at the beginning of the reaction, where the slope of the plot conversion versus time is higher. The initial slopes for catalyst masses of 1.8 and $3.0 \mathrm{~g}$ are 0.0176 and 0.0296 , respectively. The ratio between the catalyst mass is $3.0 / 1.8=1.67$, and the ratio between the initial slopes is $0.0296 / 0.0176=1.68$. These results show that the initial reaction rate increased in the same proportion as the mass of the catalyst.

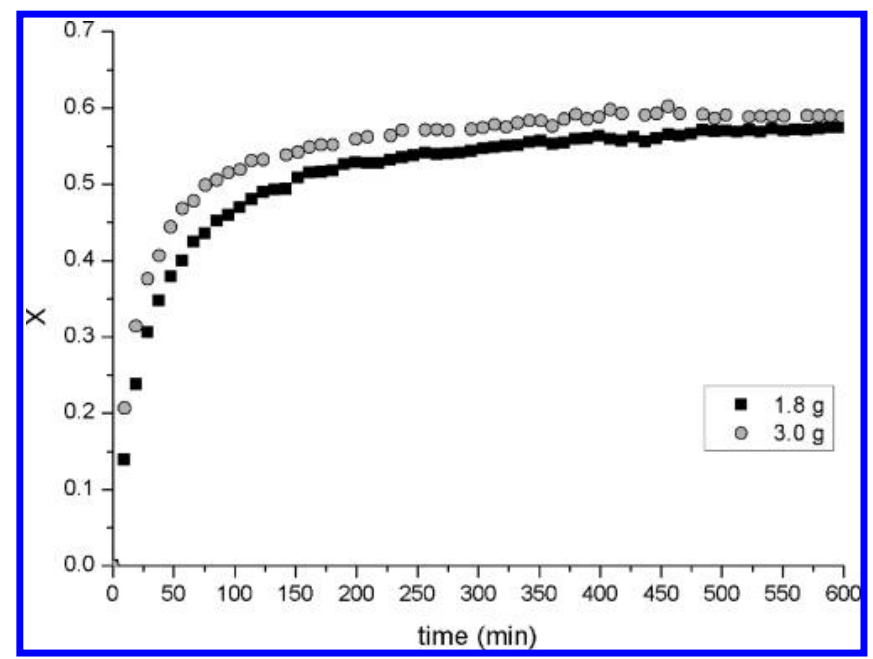

Figure 4. Effect of the mass of the catalyst on the conversion of the acetaldehyde history: $T=293.15 \mathrm{~K}, P=6 \mathrm{~atm}, r_{\mathrm{A} / \mathrm{B}}=2.2, V=530 \mathrm{~mL}$, and $0.5 \mathrm{~mm}<d_{\mathrm{p}}<0.6 \mathrm{~mm}$.

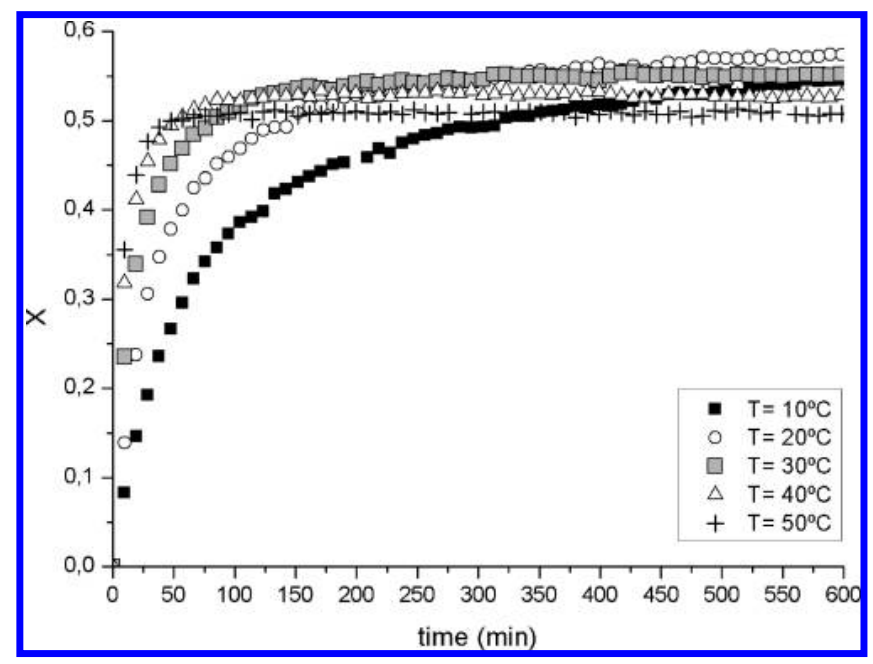

Figure 5. Effect of the temperature on the conversion of the acetaldehyde history: $P=6 \mathrm{~atm}, r_{\mathrm{A} / \mathrm{B}}=2.2, w_{\mathrm{cat}}=1.8 \mathrm{~g}, V=530 \mathrm{~mL}$, and $0.5 \mathrm{~mm}<$ $d_{\mathrm{p}}<0.6 \mathrm{~mm}$.

4.3. Effect of the Temperature. Experiments performed at different temperatures show that the rate of reaction increases with the temperature; however, the equilibrium conversion of acetaldehyde decreases because of the exothermic nature of the reaction (Figure 5). For batch or fixed-bed reactors, this could be an issue because the conversion decays from about $57 \%$ at $20{ }^{\circ} \mathrm{C}$ to about $48 \%$ at $50{ }^{\circ} \mathrm{C}$. However, from the perspective of process intensification by means of a reactive separation such as the SMBR technology, it is more important to enhance the kinetics of the reaction because equilibrium is displaced by product removal, with complete depletion of the reactants being possible to achieve. At higher temperatures, the mixture viscosity decreases, benefiting also the mass-transfer mechanisms and reducing pressure drops in the bed. Moreover, for multicomponent adsorption equilibria, the effect of the temperature on the selectivity of the resin will play a critical role. For ethyl lactate synthesis, the selectivity of water/ethyl lactate decreases by a factor of 3.5 (from 86.7 to 24.8 ) when the temperature is increased from 20 to $50{ }^{\circ} \mathrm{C} .{ }^{30}$

4.4. Effect of the Initial Molar Ratio of the Reactants. It is known that one way of increasing the conversion is to use an excess of one reactant, in order to shift the equilibrium toward product formation. However, when the catalyst productivity is 


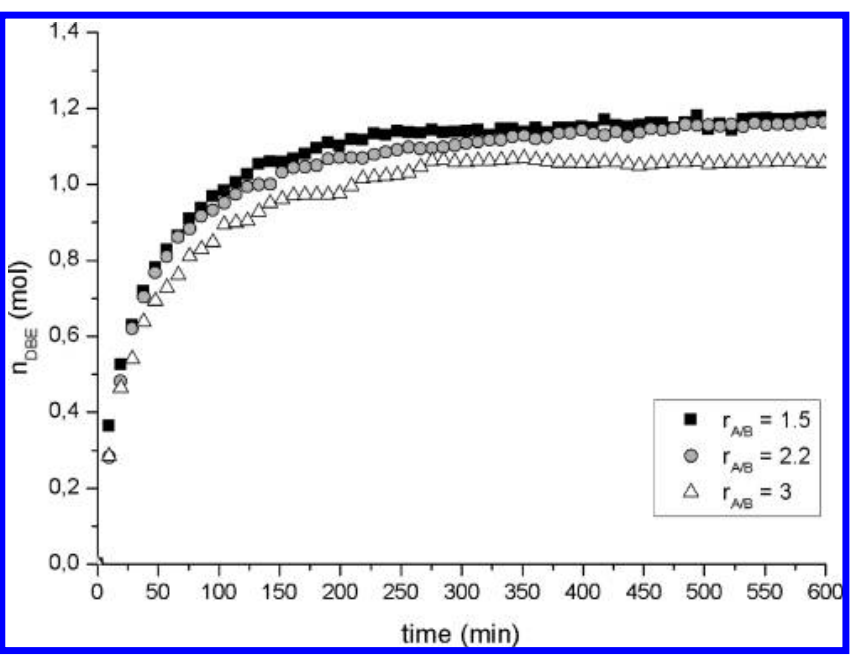

Figure 6. Effect of the initial molar ratio of the reactants on the number of moles of the DBE history: $T=293.15 \mathrm{~K}, P=6 \mathrm{~atm}, w_{\text {cat }}=1.8 \mathrm{~g}, V=$ $530 \mathrm{~mL}$, and $0.5 \mathrm{~mm}<d_{\mathrm{p}}<0.6 \mathrm{~mm}$.

analyzed for the same catalyst loading (mass of the resin per volume of reactants), the maximum quantity of DBE is achieved for the stoichiometric ratio of the reactants $\left(r_{\mathrm{A} / \mathrm{B}}=2\right)$, as shown in Figure 6. Moreover, the initial molar ratio $\left(r_{\mathrm{A} / \mathrm{B}}\right)$ does not significantly affect the rate of the reaction; therefore, there is no need to operate at a molar ratio of the reactants far from the stoichiometric one.

\section{Batch Reactor Model}

As shown in Figure 3 for particle diameters greater than 0.5 $\mathrm{mm}$, the kinetics of the reaction is affected by internal masstransfer resistances; for smaller diameter particles, it is not possible to conclude about internal mass-transfer resistances. Therefore, an isothermally operated batch reactor model that considers diffusion of the components inside the catalyst particle will be used. ${ }^{20}$ In this work, surface diffusion was neglected; however, Dogu et al. ${ }^{31}$ showed that although molecular diffusion is the main transport mechanism in macropores, surface diffusion could also have a significant contribution. From our knowledge, this behavior was not reported or noticed for esterification or acetalization reactions. Therefore, surface diffusion was not considered in this work.

Mass balance in the bulk fluid:

$$
\frac{\mathrm{d} C_{\mathrm{b}, j}}{\mathrm{~d} t}=-\left.\frac{A_{\mathrm{p}}}{V_{\mathrm{liq}}} D_{j} \frac{\partial C_{\mathrm{p}, j}}{\partial r}\right|_{r=r_{\mathrm{p}}} \quad(j=\mathrm{A}-\mathrm{D})
$$

with

$$
A_{\mathrm{p}}=\frac{3}{r_{\mathrm{p}}} V_{\mathrm{p}}
$$

where $C_{\mathrm{b}, j}$ is the bulk concentration of component $j, C_{\mathrm{p}, j}$ is the concentration of component $j$ inside the particle pores, $A_{\mathrm{p}}$ is the external area between the fluid and particle, $V_{\text {liq }}$ is the volume of liquid inside the reactor, $D_{j}$ is the effective diffusivity of component $j$ inside the particle pores (Appendix B), $r_{\mathrm{p}}$ is the particle radius, $V_{\mathrm{p}}$ is the total volume of particles, $r$ is the particle radial position, and $t$ is the time coordinate.

Mass balance in the particle:

$$
\varepsilon_{\mathrm{p}} \frac{\partial C_{\mathrm{p}, j}}{\partial t}=\frac{1}{r^{2}} \frac{\partial}{\partial r}\left[D_{j} r^{2} \frac{\partial C_{\mathrm{p}, j}}{\partial r}\right]+\left(1-\varepsilon_{\mathrm{p}}\right) v_{j} \rho_{\mathrm{s}} \mathscr{R}^{p}
$$

where $\varepsilon_{\mathrm{p}}$ is the particle porosity, $v_{j}$ is the stoichiometric coefficient of the component $j, \rho_{\mathrm{s}}$ is the true density of the resin, and $\mathscr{R}^{P}$ is the reaction rate relative to the local concentration (in $\mathrm{mol} \mathrm{g}_{\text {cat }}^{-1} \mathrm{~min}^{-1}$ ).

Initial conditions:

$$
t=0, \quad C_{\mathrm{b}, j}=C_{\mathrm{b} 0, j} ; \quad C_{\mathrm{p}, j}=C_{\mathrm{p} 0, j}
$$

Considering the external mass-transfer resistance as negligible, the boundary conditions are

$$
\begin{gathered}
r=0, \quad \frac{\partial C_{\mathrm{p}, j}}{\partial r}=0 \\
r=r_{\mathrm{p}}, \quad C_{\mathrm{b}, j}=\left.C_{\mathrm{p}, j}\right|_{r=r_{\mathrm{p}}}
\end{gathered}
$$

Upon introduction of the dimensionless space variable $\rho=r / r_{\mathrm{p}}$, the model equations become

$$
\frac{\mathrm{d} C_{\mathrm{b}, j}}{\mathrm{~d} t}=-\left.\frac{3}{r_{\mathrm{p}}^{2}} \frac{1-\varepsilon_{\mathrm{b}}}{\varepsilon_{\mathrm{b}}} D_{j} \frac{\partial C_{\mathrm{p}, j}}{\partial \rho}\right|_{\rho=1}
$$

where $\varepsilon_{\mathrm{b}}$ is the bulk porosity.

$$
\frac{\partial C_{\mathrm{p}, j}}{\partial t}=\frac{D_{j}}{r_{\mathrm{p}}^{2}} \frac{1}{\rho^{2}} \frac{\partial}{\partial \rho}\left[\rho^{2} \frac{\partial C_{\mathrm{p}, j}}{\partial \rho}\right]+\frac{1-\varepsilon_{\mathrm{p}}}{\varepsilon_{\mathrm{p}}} v_{j} \rho_{\mathrm{s}} \mathscr{R}^{p}
$$

Boundary conditions:

$$
\begin{gathered}
\rho=0, \quad \frac{\partial C_{\mathrm{p}, j}}{\partial \rho}=0 \\
\rho=1, \quad C_{\mathrm{p}, j}=\left.C_{\mathrm{p}, j}\right|_{\rho=1}
\end{gathered}
$$

5.1. Kinetic Model. In this work, the Langmuir-Hinshelwood model equation (15) was considered, following previous experience in our laboratory with diethylacetal and dimethylacetal synthesis. ${ }^{13,21}$ The reaction rate is

$$
\begin{aligned}
& \mathscr{R}= \\
& k_{\mathrm{c}} \frac{a_{\mathrm{A}} a_{\mathrm{B}}-\frac{a_{\mathrm{C}} a_{\mathrm{D}}}{K_{\mathrm{a}} a_{\mathrm{A}}}}{\left(1+K_{\mathrm{s}, \mathrm{A}} a_{\mathrm{A}}+K_{\mathrm{s}, \mathrm{B}} a_{\mathrm{B}}+K_{\mathrm{I}_{1}} a_{\mathrm{A}} a_{\mathrm{B}}+K_{\mathrm{I}_{2}} \frac{a_{\mathrm{C}}}{a_{\mathrm{A}}}+K_{\mathrm{s}, \mathrm{C}} a_{\mathrm{C}}+\right.} \\
& \left.K_{\mathrm{s}, \mathrm{D}} a_{\mathrm{C}}+K_{\mathrm{s}, \mathrm{D}} a_{\mathrm{D}}\right)^{2}
\end{aligned}
$$

This model is based on adsorption of the reactant species (butanol and acetaldehyde), the reaction between adsorbed reactants on the catalyst surface, and desorption of the reaction products (water and DBE). The surface reaction involves three steps:

Surface reaction between the adsorbed species of butanol (A) and acetaldehyde (B) to give adsorbed hemiacetal, $\mathrm{I}_{1} \mathrm{~S}$ :

$$
\mathrm{AS}+\mathrm{BS} \stackrel{K_{1}}{\Leftrightarrow} \mathrm{I}_{1} \mathrm{~S}+\mathrm{S}
$$


Table 2. Estimated Model Parameters

\begin{tabular}{lccc}
\hline & \multicolumn{3}{c}{$T(\mathrm{~K})$} \\
\cline { 2 - 4 } & 293.15 & 303.15 & 313.15 \\
\hline$k_{\mathrm{c}}\left(\mathrm{mol} \mathrm{g}^{-1} \mathrm{~min}\right)$ & 1.5761 & 3.0424 & 6.091 \\
$K_{\mathrm{s}, \mathrm{D}}$ & 16.765 & 12.338 & 8.649
\end{tabular}

Surface reaction to obtain adsorbed water, DS:

$$
\mathrm{I}_{1} \mathrm{~S}+\mathrm{S} \stackrel{K_{2}}{\Leftrightarrow} \mathrm{I}_{2} \mathrm{~S}+\mathrm{DS}
$$

Surface reaction to obtain adsorbed acetal, CS:

$$
\mathrm{I}_{2} \mathrm{~S}+\mathrm{AS} \stackrel{K_{3}}{\Leftrightarrow} \mathrm{CS}+\mathrm{S}
$$

The reaction where water is formed (step 2) was assumed to be the rate-controlling step because formation of the intermediate $I_{2}$ from the protonated hemiacetal is the ratedetermining step for acetalization. ${ }^{32,33}$ Because of the acidic property of Amberlyst-15, water will be the more adsorbed component; therefore, when the other adsorption constants are neglected, the kinetic model can be reduced to a threeparameter equation (eq 16):

$$
\mathscr{R}=k_{\mathrm{c}} \frac{a_{\mathrm{A}} a_{\mathrm{B}}-\frac{a_{\mathrm{c}} a_{\mathrm{D}}}{K_{\mathrm{a}} a_{\mathrm{A}}}}{\left(1+K_{\mathrm{s}, \mathrm{D}} a_{\mathrm{D}}\right)^{2}}
$$

\section{Numerical Solution}

The model equations were solved using the commercial software gPROMS (general PROcess Modeling System), version 3.1.5. The batch reactor model is defined by a set of partial differential equations. The radial domain was discretized using the second-order orthogonal collocation in the finite-element method (OCFEM). The system of ordinary differential equations, resulting from radial discretization, was integrated over time using DASOLV integrator implementation in $g P R O M S$. For radial discretization, 10 finite elements with two collocation points were used in each element. For all simulations, a tolerance equal to $10^{-5}$ was fixed.

6.1. Parameter Estimation. In order to determine the parameters of the reaction rate model proposed, it is necessary to find a combination of these parameters that provide the best fit of the batch reactor model results with experimental measurements.

The parameter estimation was performed in gPROMS software $^{34}$ providing the best fit of measured and predicted data using the maximum likelihood method. ${ }^{35}$

The objective function associated with the parameter estimation is described by the following equation:

$$
\Phi=\frac{N}{2} \ln (2 \pi)+\frac{1}{2} \min _{\theta}\left\{\sum_{i=1}^{\mathrm{NE}} \sum_{j=1}^{\mathrm{NV}_{i}} \sum_{k=1}^{\mathrm{NM}_{i, j}}\left[\ln \left(\sigma_{i j k}^{2}\right)+\frac{\left(\tilde{z}_{i j k}-z_{i j k}\right)^{2}}{\sigma_{i j k}{ }^{2}}\right]\right\}
$$

where $\tilde{z}_{i j k}$ and $z_{i j k}$ are the measured and predicted data, respectively, $N$ is the total number of measurements taken during the experiments, $\theta$ is the set of parameters to be estimated $\left(k_{\mathrm{c}}\right.$ and $K_{\mathrm{s}, \mathrm{D}}$ ), $\mathrm{NE}$ is the number of experiments performed, $\mathrm{NV}_{i}$ is the number of variables measured in the $i$ th experiment, $\mathrm{NM}_{i j}$ is the number of measurements of the $j$ th variable, and $\sigma_{i j k}^{2}$ is the variance of the $k$ th measurement of variable $j$ in experiment $i$.

The results of the parameter estimation for different temperatures are presented in Table 2 .

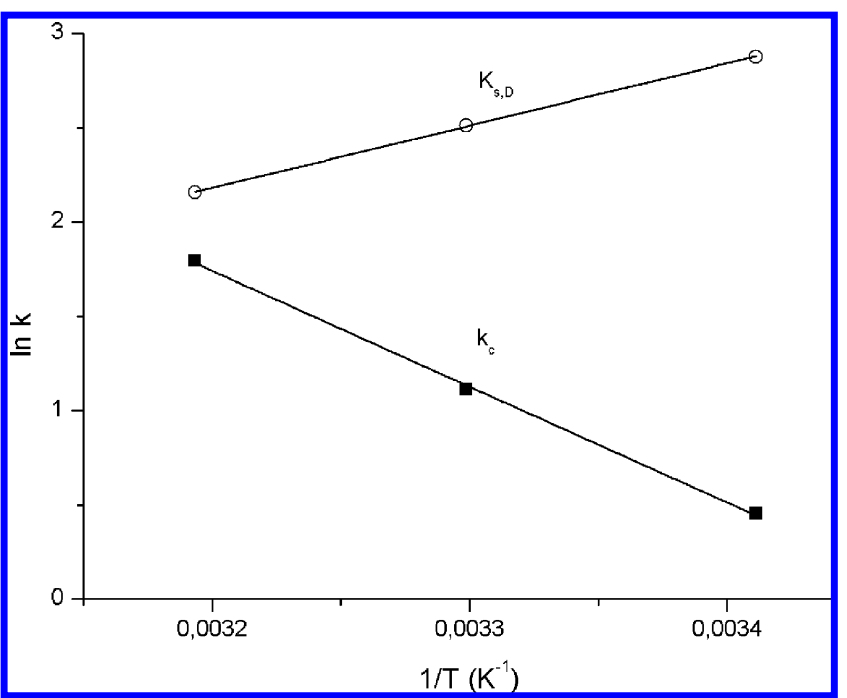

Figure 7. Representation of the experimental values of $k_{\mathrm{c}}$ and $K_{\mathrm{s}, \mathrm{D}}$ as a function of $1 / T$ and linear fitting.

Table 3. Kinetic Law and Parameters Used in Batch Reactor Model Simulations

\begin{tabular}{ll}
\hline $\begin{array}{l}\text { kinetic law } \\
\text { equilibrium constant } \\
\quad(\text { dimensionless) }\end{array}$ & $\mathscr{R}=k_{\mathrm{c}}\left[\left(a_{\mathrm{A}} a_{\mathrm{B}}-a_{\mathrm{c}} a_{\mathrm{d}} / K_{\mathrm{a}} a_{\mathrm{A}}\right) /\left(1+K_{\mathrm{s}, \mathrm{D}} a_{\mathrm{D}}\right)^{2}\right]$ \\
$\begin{array}{l}\text { kinetic constant } \\
\left(\mathrm{mol} \mathrm{g}_{\text {cat }}^{-1} \mathrm{~min}^{-1}\right)\end{array}$ & $K_{\mathrm{a}}=9.59 \times 10^{-3} \exp [1755.3 / T(\mathrm{~K})]$ \\
$\begin{array}{c}\text { water adsorption } \\
\text { constant (dimensionless) }\end{array}$ & $K_{\mathrm{s}, \mathrm{D}}=2.39 \times 10^{9} \exp [-6200.9 / T(\mathrm{~K})]$ \\
\end{tabular}

The temperature dependence of the estimated parameters is given by the Arrhenius equation:

$$
\begin{gathered}
k_{\mathrm{c}}=k_{0, \mathrm{c}} \exp \left(-\frac{E_{\mathrm{a}, \mathrm{c}}}{R T}\right) \\
k_{\mathrm{s}, \mathrm{D}}=k_{0, \mathrm{~s}} \exp \left(-\frac{\Delta H_{\mathrm{s}}}{R T}\right)
\end{gathered}
$$

The predicted values of $k_{\mathrm{c}}$ and $K_{\mathrm{S}, \mathrm{D}}$ are represented as a function of the temperature in Figure 7. By fitting of the predicted values by eq 18 and eq $19, E_{\mathrm{a}, \mathrm{c}}=51.55 \mathrm{~kJ} \mathrm{~mol}^{-1}$ and $\Delta H_{\mathrm{s}}=-27.5$ $\mathrm{kJ} \mathrm{mol}^{-1}$ are obtained.

\section{Model Results}

The kinetic law and the parameters of the batch reactor model considered in the following simulations are presented in Table 3.

Parts $\mathrm{a}$ and $\mathrm{b}$ of Figure 8 show the time evolution of the amount (moles) of reactants (butanol and acetaldehyde) and products (acetal DBE and water) at two different temperatures (293.15 and $313.15 \mathrm{~K}$ ); a comparison between the experimental and simulated results is also presented.

In order to validate the estimation of the mass-transfer parameters, experiments for different particle diameters were performed. Parts $a$ and $b$ of Figure 9 show that the model gives a good prediction of the batch reaction for both experiments and, therefore, the good agreement between the experimental and simulated results leads us to conclude that the model gives a good prediction of the effect of the internal mass-transfer resistance.

By simulation, it is possible to observe the effect of the particle diameter on the internal concentration profile. Figure 10 shows the internal concentration profile of butanol for 


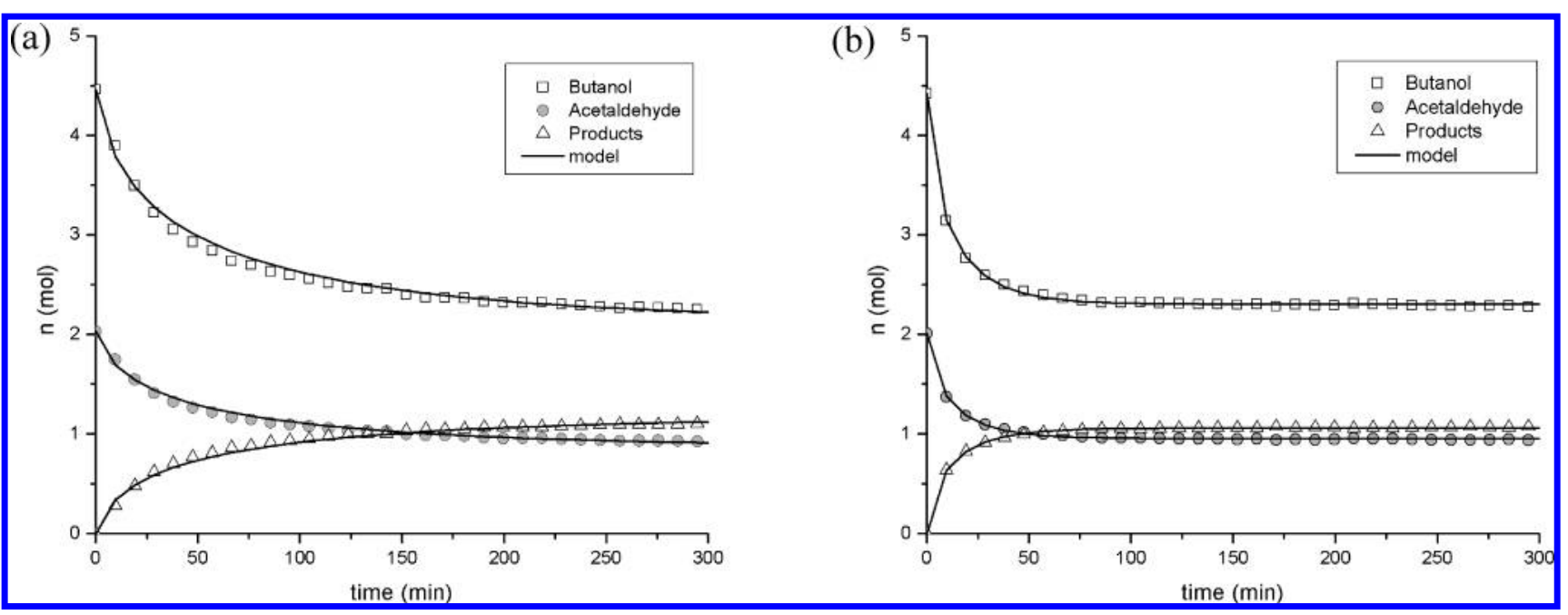

Figure 8. Experimental and simulated kinetic curves: $P=6 \mathrm{~atm}, w_{\mathrm{cat}}=1.8 \mathrm{~g}, d_{\mathrm{p}}=0.550 \mathrm{~mm}$, and $r_{\mathrm{A} / \mathrm{B}}=2.2$ for (a) $293.15 \mathrm{~K}$ and (b) $313.15 \mathrm{~K}$.

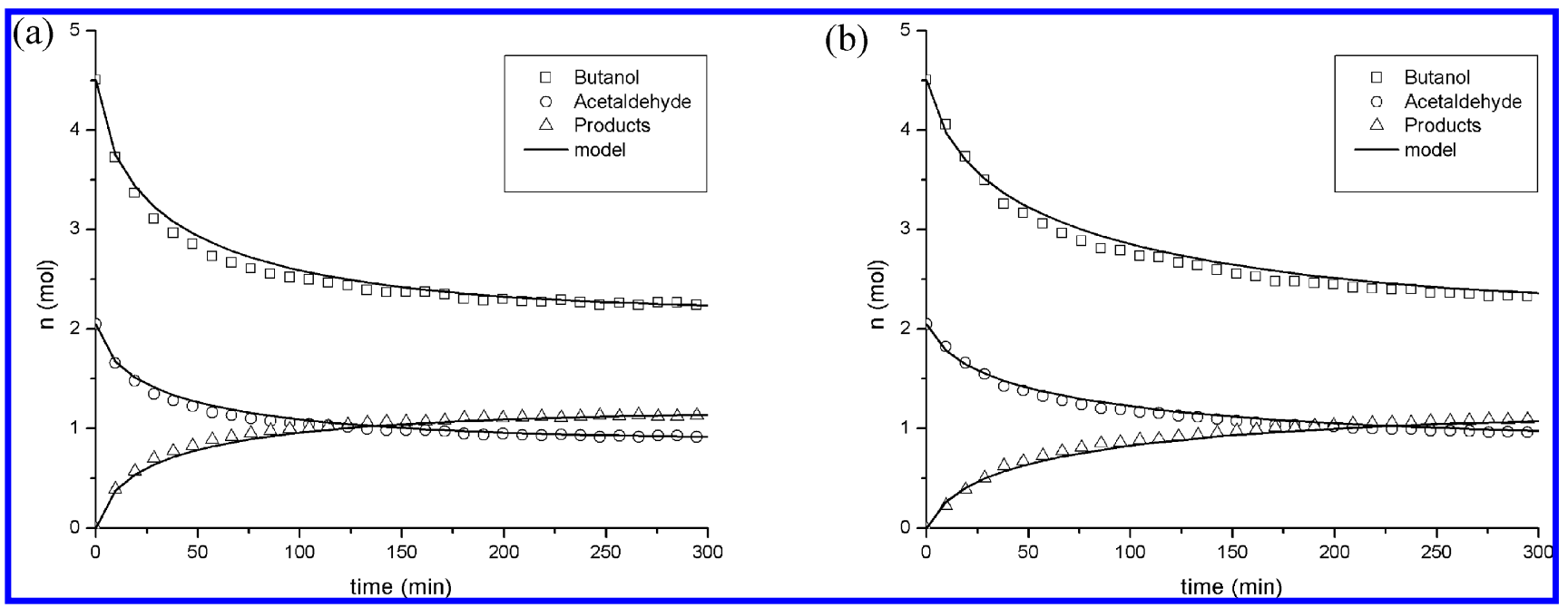

Figure 9. Experimental and simulated kinetic curves: $T=293.15 \mathrm{~K}, P=6 \mathrm{~atm}, w_{\mathrm{cat}}=1.8 \mathrm{~g}, r_{\mathrm{A} / \mathrm{B}}=2.2$ for (a) $d_{\mathrm{p}}=0.428 \mathrm{~mm}$ and (b) $d_{\mathrm{p}}=0.890 \mathrm{~mm}$.

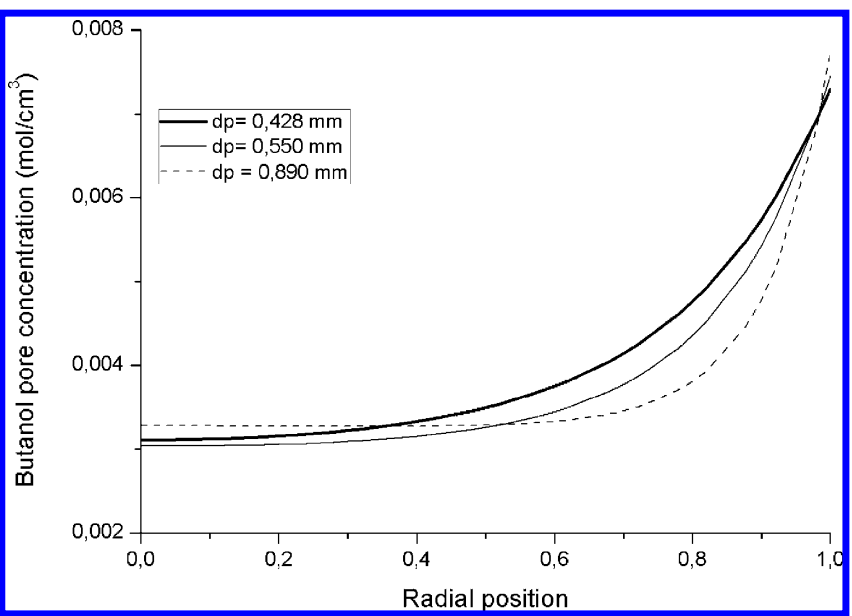

Figure 10. Internal concentration profile of butanol for $t=9.5 \mathrm{~min}$.

three particle diameters. The presence of a concentration gradient between the surface and the center of the catalyst indicates the presence on the internal mass-transfer resistances. The internal concentration profile is more abrupt for greater particle diameter, indicating that the internal mass- transfer resistance increases with the particle diameter, as was expected.

In order to evaluate how much the internal mass transfer is controlling the kinetic experiments, it is possible to calculate the catalyst effectiveness factor for each experiment, which is defined by the following expression:

$$
\eta=\frac{\langle\mathscr{R}\rangle}{\mathscr{R}_{\mathrm{s}}}=3 \frac{\int_{0}^{1} \rho^{2} \mathscr{R} \mathrm{d} \rho}{\mathscr{R}_{\mathrm{s}}}
$$

where $\mathscr{R}_{\mathrm{s}}$ is the reaction rate at surface conditions and $\langle\mathscr{R}\rangle$ is the average reaction rate defined as

$$
\langle\mathscr{R}\rangle=\frac{\int_{0}^{r_{\mathrm{p}}} r^{2} \mathscr{R} \mathrm{d} r}{\int_{0}^{r_{\mathrm{p}}} r^{2} \mathrm{~d} r}=3 \int_{0}^{1} \rho^{2} \mathscr{R} \mathrm{d} \rho
$$

The highest effectiveness factor of about $69 \%$ at equilibrium was obtained using a catalyst with an average diameter of $428 \mu \mathrm{m}$ (Figure 11). For the largest particle diameter of $890 \mu \mathrm{m}$, the effectiveness factor is about $42 \%$ at equilibrium. From this, it is possible to conclude that all experiments were performed under a diffusion-controlled regime. In order to 


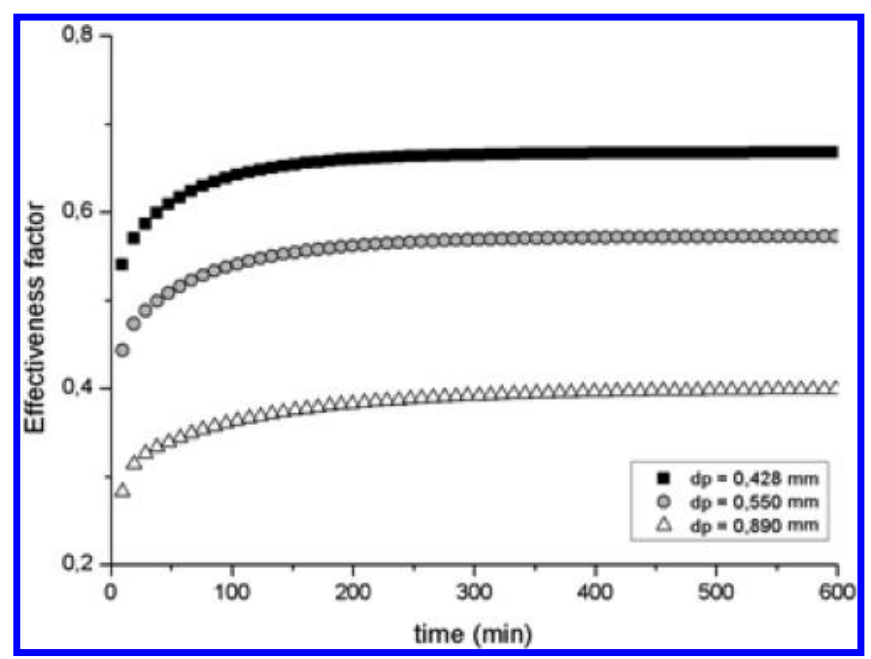

Figure 11. Effectiveness factor time evolution.

Table 4. Acetalization Reaction of Acetaldehyde with Methanol (Reaction 1), Ethanol (Reaction 2), and 1-Butanol (Reaction 3) ${ }^{a}$

\begin{tabular}{lcccc}
\hline & $X_{\mathrm{eq}}$ & $t_{1 / 2}(\mathrm{~min})$ & $\eta$ & $E_{\mathrm{a}, \mathrm{c}}\left(\mathrm{kJ} \mathrm{mol}^{-1}\right)$ \\
\hline reaction 1 & 0.63 & 40 & 0.16 & 72.4 \\
reaction 2 & 0.56 & 180 & 0.36 & 65.1 \\
reaction 3 & 0.53 & 764 & 0.61 & 51.6 \\
${ }^{a} P=6 \mathrm{~atm}, w_{\mathrm{cat}}=0.5 \mathrm{~g}, d_{\mathrm{p}}=0.550 \mathrm{~mm}, r_{\mathrm{A} / \mathrm{B}}=2$, and $T=293.15 \mathrm{~K}$.
\end{tabular}

operate under a chemical reaction-controlled regime (effectiveness factor of about 1), it would be necessary to use a particle diameter of lower than $175 \mu \mathrm{m}$, which is not commercially available, and it is not possible to grind the resin without affecting its catalytic properties. ${ }^{36}$

In Table 4, acetalization reactions of acetaldehyde with methanol, ${ }^{21}$ ethanol, ${ }^{37}$ and 1-butanol are compared with the terms of equilibrium conversion, reaction half-life, effectiveness factors, and activation energy. These results show that both the equilibrium conversion and reaction rate decrease with an increase in the chain length of the alcohol.

\section{Conclusions}

The DBE synthesis in a liquid-phase reaction catalyzed by Amberlyst-15 was studied in a laboratory-scale batch reactor. The thermodynamic equilibrium constant was calculated based on the equilibrium compositions in the temperature range of $293.15-323.15 \mathrm{~K}$ and is given by the expression $K_{\mathrm{a}}=0.00959 \exp [1755.3 / T(\mathrm{~K})]$. The reaction is exothermic, and the standard properties of the reaction at $298.15 \mathrm{~K}$ are $\Delta H^{\circ}=-14593.6 \mathrm{~J} \mathrm{~mol}^{-1}, \Delta S^{\circ}=-38.6 \mathrm{~J}$ $\mathrm{mol}^{-1} \mathrm{~K}^{-1}$, and $\Delta G^{\circ}=-3074.1 \mathrm{~J} \mathrm{~mol}^{-1}$.

Kinetic experiments showed that the rate of reaction increases with the temperature; however, the equilibrium conversion decreases with the temperature because of the exothermic nature of the reaction. Experiments performed at different particle diameters showed the existence of internal mass-transfer resistances for particle diameters greater than $0.5 \mathrm{~mm}$.

Because of the strong nonideality of the liquid reaction mixture, both the equilibrium constant and kinetic law were expressed in terms of activities. The activation energy of $51.55 \mathrm{~kJ} \mathrm{~mol}^{-1}$ was calculated by fitting the estimated kinetic parameters at different temperatures to the Arrhenius equation.

A comparison between the experimental and simulated results shows that the model gives a good representation of
Table A1. Relative Molecular Volume and Surface Parameters of a Pure Species $^{38}$

\begin{tabular}{|c|c|c|c|c|c|c|}
\hline \multirow[b]{2}{*}{ molecule $i$} & \multicolumn{3}{|c|}{ group identification } & \multirow[b]{2}{*}{$v_{k}^{(i)}$} & \multirow[b]{2}{*}{$R_{k}$} & \multirow[b]{2}{*}{$Q_{k}$} \\
\hline & name & $\begin{array}{c}\text { no. of } \\
\text { main groups }\end{array}$ & $\begin{array}{c}\text { no. of } \\
\text { secondary groups }\end{array}$ & & & \\
\hline \multirow{3}{*}{ 1-butanol } & $\mathrm{CH}_{3}$ & 1 & 1 & 1 & 0.9011 & 0.848 \\
\hline & $\mathrm{CH}_{2}$ & 1 & 2 & 3 & 0.6744 & 0.540 \\
\hline & $\mathrm{OH}$ & 5 & 15 & 1 & 1.0000 & 1.200 \\
\hline \multirow[t]{2}{*}{ acetaldehyde } & $\mathrm{CH}_{3}$ & 1 & 1 & 1 & 0.9011 & 0.848 \\
\hline & $\mathrm{CHO}$ & 10 & 21 & 1 & 0.9980 & 0.948 \\
\hline \multirow[t]{4}{*}{ DBE } & $\mathrm{CH}_{3}$ & 1 & 1 & 3 & 0.9011 & 0.848 \\
\hline & $\mathrm{CH}_{2}$ & 1 & 2 & 4 & 0.6744 & 0.540 \\
\hline & $\mathrm{CH}$ & 1 & 3 & 1 & 0.4469 & 0.228 \\
\hline & $\mathrm{CH}_{2} \mathrm{O}$ & 13 & 26 & 2 & 0.9183 & 0.780 \\
\hline water & $\mathrm{H}_{2} \mathrm{O}$ & 7 & 17 & 1 & 0.8200 & 1.400 \\
\hline
\end{tabular}

Table A2. Interaction Parameters ${ }^{28}$

\begin{tabular}{lccccc}
\hline & \multicolumn{5}{c}{$a_{m, n}$} \\
\cline { 2 - 6 }$a_{m, n}$ & 1 & 5 & 7 & 10 & 13 \\
\hline 1 & 0 & 986.5 & 1318 & 677 & 251.5 \\
5 & 156.4 & 0 & 353.5 & -203.6 & 28.06 \\
7 & 300 & -229.1 & 0 & -116 & 540.5 \\
10 & 505.7 & 529 & 480.8 & 0 & 304.1 \\
13 & 83.36 & 237.7 & -314.7 & -7.838 & 0
\end{tabular}

Table A3. Pure-Component Liquid Molar Volume and Viscosity for Different Temperatures ${ }^{45}$

\begin{tabular}{|c|c|c|c|c|c|c|c|c|}
\hline \multirow[b]{2}{*}{$T(\mathrm{~K})$} & \multicolumn{4}{|c|}{ liquid molar volume $\left(\mathrm{mL} \mathrm{mol}^{-1}\right)$} & \multicolumn{4}{|c|}{ viscosity $(\mathrm{cP})$} \\
\hline & $V_{\mathrm{A}}$ & $V_{\mathrm{B}}$ & $V_{\mathrm{C}}$ & $V_{\mathrm{D}}$ & A & $\eta_{\mathrm{B}}$ & $\eta_{\mathrm{C}}$ & $\eta_{\mathrm{D}}$ \\
\hline & 9 & & & & 2.899 & 0.2 & 11 & \\
\hline 303.15 & 92.4 & 57. & 2 & 18. & 2.249 & 0.223 & 0.988 & 0.78 \\
\hline 313.15 & 93. & 58 & 217 & 18 & 1.780 & 0.220 & 0.820 & 0.64 \\
\hline 323.15 & 94.24 & 59.60 & 222.43 & 18.23 & 1.411 & 0.214 & 0.679 & 0.544 \\
\hline
\end{tabular}

Table A4. Liquid Mixture Viscosity and Molecular Diffusivities Calculated Based on the Equilibrium Composition (Table 1)

\begin{tabular}{cccccc}
\hline & liquid mixture & \multicolumn{4}{c}{ molecular diffusivity $\left(\mathrm{cm}^{2} \mathrm{~s}^{-1}\right) \times 10^{5}$} \\
\cline { 3 - 6 }$T(\mathrm{~K})$ & viscosity $\eta_{\mathrm{m}}(\mathrm{cP})$ & $D_{\mathrm{A}, \mathrm{m}}$ & $D_{\mathrm{B}, \mathrm{m}}$ & $D_{\mathrm{C}, \mathrm{m}}$ & $D_{\mathrm{D}, \mathrm{m}}$ \\
\hline 293.15 & 0.923 & 1.654 & 2.191 & 0.490 & 6.930 \\
303.15 & 0.796 & 1.994 & 2.704 & 0.566 & 8.538 \\
313.15 & 0.695 & 2.386 & 3.321 & 0.639 & 10.468 \\
323.15 & 0.601 & 2.871 & 4.060 & 0.736 & 12.844
\end{tabular}

the batch reactor performance for different temperatures and particle diameters of the catalyst. The simulated results of the catalyst internal concentration profiles showed a concentration gradient between the surface and the center of catalyst because of the presence of internal mass-transfer resistances. The time evolution of the effectiveness factor, for different particle diameters, shows that the controlling mechanism is the internal diffusion.

This work is an important step for further implementation of an integrated reaction-separation process, such as a SMBR, in order to enhance the conversion of the reaction limited by chemical equilibrium.

\section{Acknowledgment}

N.S.G. acknowledges Fundação para a Ciência e a Tecnologia for the Ph.D. Research Fellowship SFRH/BD/41107/2007.

\section{Appendix A. UNIFAC Method Parameters}

Tables A1 and A2 present the UNIFAC method parameters used in this work to calculate the activity coefficients $\left(\gamma_{i}\right)$. 


\section{Appendix B. Effective Diffusivity Calculation}

The effective diffusivity $D_{j}$ of the compound $j$ is given by

$$
D_{j}=\frac{\varepsilon_{\mathrm{p}} D_{j, \mathrm{~m}}}{\tau}
$$

where $D_{j, \mathrm{~m}}$ is the molecular diffusivity of compound $j$ in the multicomponent mixture and $\tau$ is the tortuosity of an ionexchange resin. The coefficients $D_{j, \mathrm{~m}}$ were estimated in a way similar to that performed to the system of ethyl lactate synthesis; once one reactant (lactic acid solution) has a high viscosity, similarly to this case, where butanol is very viscous also. ${ }^{30}$ Different values of $\tau_{\mathrm{p}}$, such as $1.3,{ }^{39} 2,{ }^{40}$ and $4.9,{ }^{41}$ are reported in the literature for calculation of the effective diffusivity in Amberlyst-15. Estimations of the tortuosity were made using the correlations given by Wakao and $\operatorname{Smith}^{42}\left(\tau_{\mathrm{p}}=1 / \varepsilon_{\mathrm{p}}\right)$ and Suzuki and $\operatorname{Smith}^{43}\left[\tau_{\mathrm{p}}=\varepsilon_{\mathrm{p}}+1.5\left(1-\varepsilon_{\mathrm{p}}\right)\right]$; the values obtained with $\varepsilon_{\mathrm{p}}=0.36$ were 2.78 and 1.32 , respectively. In this work, the tortuosity used was 2 , i.e., the mean between the estimated values.

The infinite dilution molecular diffusivities were estimated by the Scheibel correlation, which modified the Wilke-Chang equation in order to eliminate its association factor: ${ }^{44}$

$$
D_{j, i}^{0}=\frac{8.2 \times 10^{-8}}{\eta_{i} V_{j}^{1 / 3}}\left[1+\left(\frac{3 V_{i}}{V_{j}}\right)^{2 / 3}\right]
$$

where $D_{j, i}^{0}$ is the diffusion coefficient for a dilute solute $j$ in a solvent $i, V_{j}$ is the molar volume of the component $j$, and $\eta_{i}$ is the viscosity of solvent $i$. Table A3 presents the liquid molar volume and viscosity for the pure components.

For a concentrated multicomponent system, the Perkins and Geankoplis ${ }^{46}$ method was used:

$$
D_{j, \mathrm{~m}} \eta_{\mathrm{m}}{ }^{0.8}=\sum_{\substack{i=1 \\ i \neq j}}^{n} x_{i} D_{j, i}^{0} \eta_{i}^{0.8}
$$

The viscosity of the liquid mixture was calculated by the Grunberg-Nissan approach: ${ }^{47}$

$$
\ln \left(\eta_{\mathrm{m}}\right)=x_{1} \ln \left(\eta_{1}\right)+x_{2} \ln \left(\eta_{2}\right)+x_{1} x_{2} G_{1,2}
$$

where $G_{1,2}$ is an empirical interaction parameter adjusted by the experimental data. The liquid mixture viscosity and the molar diffusivities are presented in Table A4.

\section{Appendix C}

\section{Notation}

$a=$ liquid-phase activity

$A_{\mathrm{p}}=$ external exchange area between the bulk and the particles

$C_{i}=$ concentration, $\mathrm{mol} \mathrm{cm} \mathrm{cm}^{-3}$

$C_{\mathrm{b}}=$ bulk concentration, $\mathrm{mol} \mathrm{\textrm {cm } ^ { - 3 }}$

$C_{\mathrm{p}}=$ concentration inside the particle, $\mathrm{mol} \mathrm{min}^{-3}$

$d_{\mathrm{p}}=$ average particle diameter, $\mathrm{mm}$

$D_{j}=$ effective diffusivity, $\mathrm{cm}^{2} \mathrm{~min}^{-1}$

$D_{j, \mathrm{~m}}=$ molecular diffusivity coefficient of a solute in a mixture, $\mathrm{cm}^{2} \min ^{-1}$

$E_{\mathrm{a}, \mathrm{c}}=$ reaction activation energy, $\mathrm{kJ} \mathrm{mol}^{-1}$

$\Delta G^{\circ}=$ standard Gibbs free energy, $\mathrm{J} \mathrm{mol}^{-1}$

$\Delta H^{\circ}=$ standard enthalpy, $\mathrm{J} \mathrm{mol}^{-1}$

$\Delta H_{\mathrm{s}}=$ enthalpy of adsorption, $\mathrm{J} \mathrm{mol}^{-1}$

$k_{\mathrm{c}}=$ kinetic constant, mol $\mathrm{g}_{\mathrm{cat}}{ }^{-1} \mathrm{~min}$

$k_{0, \mathrm{c}}=$ Arrhenius constant for eq $18, \mathrm{~mol} \mathrm{~g}_{\mathrm{cat}}{ }^{-1} \mathrm{~min}$ $k_{0, \mathrm{~s}}=$ Arrhenius constant for eq $19, \mathrm{~mol} \mathrm{~g}_{\mathrm{cat}}{ }^{-1} \mathrm{~min}$

$K_{\mathrm{a}}=$ equilibrium constant based on activities

$K_{\mathrm{x}}=$ equilibrium constant based on the molar fraction

$K_{\gamma}=$ equilibrium constant based on activity coefficients

$K_{\mathrm{s}}=$ equilibrium adsorption constant

$n=$ number of moles, mol

$P=$ pressure, atm

$R=$ gas constant, $\mathrm{J} \mathrm{mol}^{-1} \mathrm{~K}^{-1}$

$r=$ radial position, $\mathrm{cm}$

$r_{\mathrm{p}}=$ particle radius, $\mathrm{mm}$

$r_{\mathrm{A} / \mathrm{B}}=$ initial molar ratio of the reactants

$\Delta S^{\circ}=$ standard entropy, $\mathrm{J} \mathrm{mol}^{-1} \mathrm{~K}^{-1}$

$\mathscr{R}=$ reaction rate, mol $\mathrm{g}_{\text {cat }}{ }^{-1} \mathrm{~min}$

$\mathscr{R}_{\mathrm{s}}=$ reaction rate at surface conditions, $\mathrm{mol} \mathrm{g}_{\mathrm{cat}}{ }^{-1} \mathrm{~min}$

$\langle\mathscr{R}\rangle=$ average reaction rate, $\mathrm{mol} \mathrm{g}_{\mathrm{cat}}^{-1} \mathrm{~min}$

$\mathscr{R}^{\mathrm{p}}=$ reaction rate relative to the local pore concentration, mol $\mathrm{g}_{\text {cat }}{ }^{-1} \min$

$t=$ time coordinate, $\min$

$T=$ temperature, $\mathrm{K}$

$x=$ molar fraction

$X=$ conversion of the limiting reactant

$V=$ volume of the solution, $\mathrm{cm}^{3}$

$V_{\text {liq }}=$ total volume of the reactant mixture, $\mathrm{cm}^{3}$

$V_{\mathrm{p}}=$ total volume of the particles, $\mathrm{cm}^{3}$

$w_{\text {cat }}=$ mass of the dry catalyst, $\mathrm{g}$

Greek Letters

$\gamma=$ activity coefficient

$\varepsilon_{\mathrm{b}}=$ bulk porosity

$\varepsilon_{\mathrm{p}}=$ particle porosity

$\eta=$ effectiveness factor

$\rho=$ dimensionless radial coordinate

$\rho_{\mathrm{p}}=$ particle density, $\mathrm{g} \mathrm{cm}^{-3}$

$v=$ stoichiometric coefficient

$\tau_{\mathrm{p}}=$ tortuosity factor

Subscripts

$\mathrm{A}=$ butanol

$\mathrm{B}=$ acetaldehyde

$\mathrm{C}=\mathrm{DBE}$

$\mathrm{D}=$ water

$i=$ relative to component $i$

liq = liquid phase

$\mathrm{p}=$ relative to the particle

$\mathrm{s}=$ relative to the surface of the particle

\section{Literature Cited}

(1) Wen, L. B.; Xin, C. H.; Yang, S. C. Effect of adding dimethyl carbonate $(D M C)$ and ethanol to unleaded gasoline on exhaust emission. Published online, July 17, 2009, by Elsevier.

(2) Miyamoto, N.; Ogawa, H.; Obata, R.; Arima, T. Smokeless, Low Nox, High thermal efficiency, and low noise diesel combustion with oxygenated agents as main fuel; Publication SAE-98506; Society of Automotive Engineers: Washington, DC, 1998.

(3) Li, T.; Suzuki, M.; Ogawa, H. Effects of ethyl tert-butyl ether addiction to diesel fuel on characteristics of combustion and exhaust emissions of diesel engines. Fuel 2009, 88, 2017-2024.

(4) Naegeli, D.; Dodge, L. Combustion Characterization of Methylal in Reciprocating Engines. Final Report No. SwRI 03-130; Southwest Research Institute: San Antonio, TX, 1992.

(5) Frusteri, F.; Spadaro, L.; Beatrice, C.; Guido, C. Oxygenated additives production for diesel engine emission improvement. Chem. Eng. J. 2007, 134, 239-245.

(6) Iwasaky, H.; Kitayama, M.; Onishi, T. Process for producing acetals. U.S. Patent 5,792,876, 1998.

(7) Kohlpaintner, C.; Schulte, M.; Falbe, J.; Lappe, P.; Weber, J. Aldehydes, Aliphatic and Araliphatic. Ullmann's Encyclopedia of Industrial Chemistry; Wiley-VCH: Weinheim, Germany; 1999 (electronic release). 
(8) Yadav, G. D.; Pujari, A. A. Kinetics of acetalization of perfumery aldehydes with alkanols over solid acid catalysts. Can. J. Chem. Eng. 1999, 77, 489-496.

(9) Hille, M. L.; Weinelt, F. B.; Wittikus, H.; Reimann, W. Environmentally friendly diesel fuel. U.S. Patent 6,013,114, 2000.

(10) Egwaw, T.; Kawaguchi Y.; Mogami, K.; Shimizu N. Method of producing a polyvinyl ether compound. U.S. Patent 5,616,812, 1997.

(11) Weizmann, C. Process for carrying out condensation reactions. U.S. Patent 2,474,175, 1949.

(12) Guinot, H. M. Process for the Manufacture of Acetal. U.S. Patent $1,850,836,1932$.

(13) Silva, V. M. T. M.; Rodrigues, A. E. Synthesis of diethylacetal: thermodynamics and kinetic studies. Chem. Eng. Sci. 2001, 56, 1255-1263.

(14) Düre, P. Biobutanol: An alternative biofuel. Biotchnol. J. 2007, 2, $1525-1534$

(15) Kaufhold, M. M.; El-Chabawi, M. T. Process for Preparing Acetaldehyde Diethyl Acetal. U.S. Patent 5,527,969, 1996.

(16) Lilja, J.; Murzin, D. Y.; Salmi, T.; Aumo, J.; Mäki-Avela, P.; Sundell, M. Esterification of different acids over heterogeneous and homogeneous catalyst and correlation with Taft equation. J. Mol. Catal. A: Chem. 2002, 182-183, 555-563.

(17) Kolah, A. K.; Asthana, N. S.; Vu, D. T.; Lira, C. T.; Miller, D. J. Reaction kinetics of the catalytic esterification of citric acid with ethanol. Ind. Eng. Chem. Res. 2007, 46, 3180-3187.

(18) Andrade, J.; Arntz, D.; Prescher, G. Method for Preparation of Acetals. U.S. Patent 4,579,979, 1986.

(19) Capeletti, M. R.; Balzano, L.; de la Poente, G.; Laborde, M.; Sadran, U. Synthesis of acetal (1,1-diethoxyethane) from ethanol and acetaldehyde over acidic catalyst. Appl. Catal., A 2000, 198, L1-L4.

(20) Silva, V. T. M.; Rodrigues, A. E. A Novel Process for Diethylacetal Synthesis. AIChE J. 2005, 51, 2752-2768.

(21) Gandi, G. K.; Silva, V. M. T. M.; Rodrigues, A. E. Process development for the dimethylacetal synthesis: thermodynamics and kinetic studies. Ind. Eng. Chem. Res. 2005, 44, 7287-7297.

(22) Gandi, G. K.; Silva, V. M. T. M.; Rodrigues, A. E. Acetaldehyde dimethylacetal synthesis with Smopex 101 fibers as catalyst/adsorbent. Chem. Eng. Sci. 2007, 62, 907-918.

(23) Rat, M.; Zahedi-Niaki, M. H.; Kaliaguine, S.; Do, T. O. Sulfonic acid functionalized periodic mesoporous organosilicas as acetalization catalyst). Microporous Mesopouros Mater. 2008, 112, 26-31.

(24) Mahajani, S. M.; Kolah, A. K.; Sharma, M. M. Extractive reactions with cationic exchange resins catalysts (acetalization of aldehydes with alcohols). React. Funct. Polvm. 1995, 28, 29-38.

(25) Blagova, S.; Parada, S.; Bailer, O.; Moritz, P.; Lam, D.; Weinand, R.; Hasse, H. Influence of ion-exchange resin catalyst on side reactions of the esterification of $n$-Butanol with acetic acid. Chem. Eng. Sci. 2006, 61, $753-765$.

(26) Silva, V. M. T. M.; Gandi, G. K.; Rodrigues, A. E. Development of Simulated Moving Bed Reactor Using a Cation Exchange Resin as a Catalyst and Adsorbent for the Synthesis of Acetals. In Ion Exchange and Solvent Extraction: A Series of Advances; Sen Gupta, A. K., Ed.; CRC: Boca Raton, FL, 2007; Vol. 18.

(27) Sanz, M. T.; Murga, R.; Beltrán, S.; Cabezas, J. L.; Coca, J. Kinetic for the reactive system of lactic acid esterification with methanol: methyl lactate hydrolysis reaction. Ind. Eng. Chem. Res. 2004, 43, 2049-2053.

(28) Fredeslund, A.; Gmehling, J.; Rasmussen, P. Vapor-liquid Equilibrium Using UNIFAC; Elsevier: Amsterdam, The Netherlands, 1977.

(29) Xu, Z. P.; Chuang, K. T. Effect of internal diffusion on heterogeneous catalytic esterification of acetic acid. Chem. Eng. Sci. 1997, 52, 30113017 .
(30) Pereira, C. S. M.; Silva, V. M. T. M.; Rodrigues, A. E. Fixed Bed Adsorptive Reactor for Ethyl Lactate Synthesis: Experiments, Modelling, and Simulation. J. Sep. Sci.Technol. 2009, 44, 2721-2749.

(31) Dogu, T.; Aydin, E.; Boz, N.; Murtezaoglu, K.; Dogu, G. Diffusion Resistances and Contribution of Surface Diffusion in TAME and TAEE Production Using Amberlyst-15. Int. J. Chem. React. Eng. 2003, 1, A6.

(32) Morrison, R.; Boyd, R. Organic Chemistry; Allyn and Bacon: Boston, 1983.

(33) Jermy, B. R.; Pandurangan, A. Al-MCM-41 as an efficient heterogeneous catalyst in the acetalization of cyclohexanone with methanol, ethylene glycol and pentaerythritol. J. Mol. Catal. A: Chem. 2006, 256, 184-192.

(34) gPROMS. Advanced User Guide. Process Systems; Enterprise Ltd.: London, 2002.

(35) Pereira, C. M.; Pinho, S. P.; Silva, V. M. T.; Rodrigues, A. E. Thermodynamic equilibrium and reaction kinetics for the esterification of lactic acid with ethanol catalyzed by acid ion exchange resin. Ind. Eng. Chem. Res. 2007, 47, 1453-1463.

(36) Pöpken, T.; Götze, L.; Gmehling, J. Reaction kinetics and chemical equilibrium of homogeneously and heterogeneously catalyzed acetic acid esterification with methanol and methyl acetate hydrolysis. Ind. Eng. Chem. Res. 2000, 39, 2601-2611.

(37) Silva, V. M. T. M.; Rodrigues, A. E. Kinetic Studies in a Batch Reactor using Ion-Exchange Resin Catalysts for Oxygenates Production: the Role of Mass Transfer Mechanisms. Chem. Eng. Sci. 2006, 61, 316331.

(38) Reid, C. R.; Prausnitz, J. M.; Poling, B. E. The Properties of Gases \& Liquids; McGraw-Hill: New York, 1987.

(39) Yu, W.; Hidajat, K.; Ray, A. K. Determination of Adsorption and Kinetic Parameters for Methyl Acetate Esterification and Hydrolysis Reaction Catalyzed by Amberlyst 15. Appl. Catal., A 2004, 260, 191-205.

(40) Silva, V. M. T. M. Diethylacetal synthesis in simulated moving bed reactor. Ph.D Thesis, University of Porto, Porto, Portugal, 2003.

(41) Oktar, N.; Mürtezauglu, K.; Dogu, T.; Dogu, G. Dynamic Analysis of Adsorption Equilibrium and Rate Parameters of Reactants and Products in MTBE, ETBE and TAME Production. Can. J. Chem. Eng. 1999, 77, $406-412$.

(42) Wakao, N.; Smith, J. M. Diffusion in Catalyst Pellets. Chem. Eng. Sci. 1962, 17, 256-264.

(43) Suzuki, M.; Smith, J. M. Axial Dispersion in Beds of Small Particles. Chem. Eng. J. 1972, 3, 256-264.

(44) Scheibel, E. G. Liquid diffusivities, Viscosity of gases. Ind. Eng. Chem. 1954, 46, 2007-2009.

(45) Rowley, R. L.; Wilding, W. V.; Oscarson, J. L.; Zundel, N. A.; Marshall, T. L.; Daubert, T. E.; Danner, R. P. DIPPR® Data Compilation of Pure Compound Properties; Design Institute for Physical Properties, AIChE: New York, 2002.

(46) Perkins, L. R.; Geankopolis, C. J. Molecular diffusion in ternary liquid system with diffusing component dilute. Chem. Eng. Sci. 1969, 24, 1035-1042.

(47) Grunberg, L.; Nissan, A. H. Mixture law for viscosity. Nature 1949, 164, 799-800.

Received for review October 19, 2009 Revised manuscript received March 18, 2010 Accepted March 26, 2010

IE901635J 